\title{
Controlled release strategy of paclitaxel by conjugating to matrix metalloproteinases- 2 sensitive peptide
}

\author{
Changjiang Huang ${ }^{1,2}$, Xiulin $\mathbf{Y i}^{2}$, Dexin Kong ${ }^{3}$, Ligong Chen ${ }^{1}$, Gong Min ${ }^{3,4}$ \\ ${ }^{1}$ School of Chemical Engineering and Technology, Tianjin University, Tianjin, China \\ ${ }^{2}$ Tianjin Institute of Pharmaceutical Research, Tianjin, China \\ ${ }^{3}$ School of Pharmacy, Tianjin Medical University, Tianjin, China \\ ${ }^{4}$ Department of Oncology, University of Oxford, Oxford, UK \\ Correspondence to: Gong Min, email: kahongmg@163.com \\ Ligong Chen, email: Igchen@tju.edu.cn
}

Keywords: matrix metalloproteinase, tumor targeting peptide, drug conjugate, paclitaxel, tumor metastasis

Received: April 25, 2016

Accepted: May 29, 2016

Published: July 20, 2016

\section{ABSTRACT}

Peptide drug conjugates offer a novel strategy to achieve controlled drug release. This approach avoids the clinical obstacles of non-specific toxicity and overall drug resistance of conventional cytotoxic agents, such as paclitaxel. MMP2 plays important functions in tumour proliferation and metastasis. Herein, we conjugated the paclitaxel with a hexapeptide which is specific recognized by MMP2 protein. The conjugate is dissociated upon the MMP2 specific proteolysis at COOH terminal of hexapeptide, PVGLIG.

The results clearly indicated that the PVGLIG-paclitaxel conjugate significantly enhanced the tumor specificity against HT-1080 and U87-MG tumour cells. Our finding suggested that the hexapeptide PVGLIG is capable to act as a controlled and sustained drug carrier of paclitaxel for the treatment against tumour proliferation and metastasis with high MMP2 expression.

\section{INTRODUCTION}

Matrix metalloproteinases (MMPs) are well known, as they play important functions in tumour proliferation and metastasis [1-3]. In the past decade, many studies have demonstrated that overexpression of MMP2 and MMP9 plays a vital role in metastatic tumour cells, promoting tumour growth and angiogenesis in the tumour, thereby providing nutrition to the tumour through the newly generated vessels [4-7]. In animals, MMP2 inhibitors prevented tumor dissemination and the formation of metastases by antiangiogenic properties [8-12].

The specific protease activity of MMPs has made it an attractive approach for controlling drug release. The MMPs associated peptide drug conjugate (PDC) is designed for enzymatically metabolized prodrugs, in which therapeutic drugs are covalently bound to MMP substrate peptides [13-15]. The prodrug is then dissociated with the peptides by proteolysis of MMPs. Recently, several MMP associated PDCs have been developed in order to improve the tumor specificity of small chemical agents, including paclitaxel, doxorubicin, methotrexate and so on $[16,17]$. In contrast to the original therapeutic approach of using small molecular inhibitors of MMPs, these novel drug-targeting strategies resulted in an improved therapeutic index and less toxicity [18-20].

In this study, a novel MMP2 specific hexapeptide was screened out using phage display technology, and then paclitaxel was conjugated. Initially, the antitumor activities of conjugate were investigated in vitro and in vivo. Data indicated that the conjugate possessed specificity for various tumour cell lines and tumourbearing mice. In addition, the release of paclitaxel from conjugate was analysed using LC-MS which is crucial to overcome the main obstacle in the development of MMP2 associated drug candidate.

\section{RESULTS}

A novel hexapeptide, PVGLIG, was screened out since its high binding affinity to MMP2 protein. The peptide was then conjugated with paclitaxel for achieving improvement on tumor cells selectivity. In this study, 
paclitaxel was chemically linked to the $\mathrm{COOH}$-terminus in peptide (Figure 1). Mass spectrophotometry was performed in order to monitor the reaction and to identify the final product (Figure 1).

A clear understanding about the dissociation of conjugate conjugate in vitro is necessary to ascertain the appropriate dose of the conjugate in further animal experiments. Initially, the conjugate was incubated with MMP2 protein and the free paclitaxel was monitored. Result indicated that the free paclitaxel was started to release from conjugate $2 \mathrm{~h}$ after incubation with MMP2 protein. The concentration of free paclitaxel peaked to a plateau at 4-12 h (Figure 2A). The dissociation pattern of conjugate incubated with HT-1080 and U87MG cells exhibited similar feature with that of incubation with MMP2 protein, (Figure 2B). However, there is almost none of free paclitaxel dissociated from conjugate with in the $48 \mathrm{~h}$ incubation with Hep- 2 and Hep G2 cell lines (Figure 2B). The specificity of conjugate in HT-1080 and U87MG tumor cells was derived from various expression levels of MMP2 in cells.

In addition, the cellular MTT and scratch assays were performed for evaluating the inhibition activity of conjugate on tumor metastasis. From MTT assay, shown
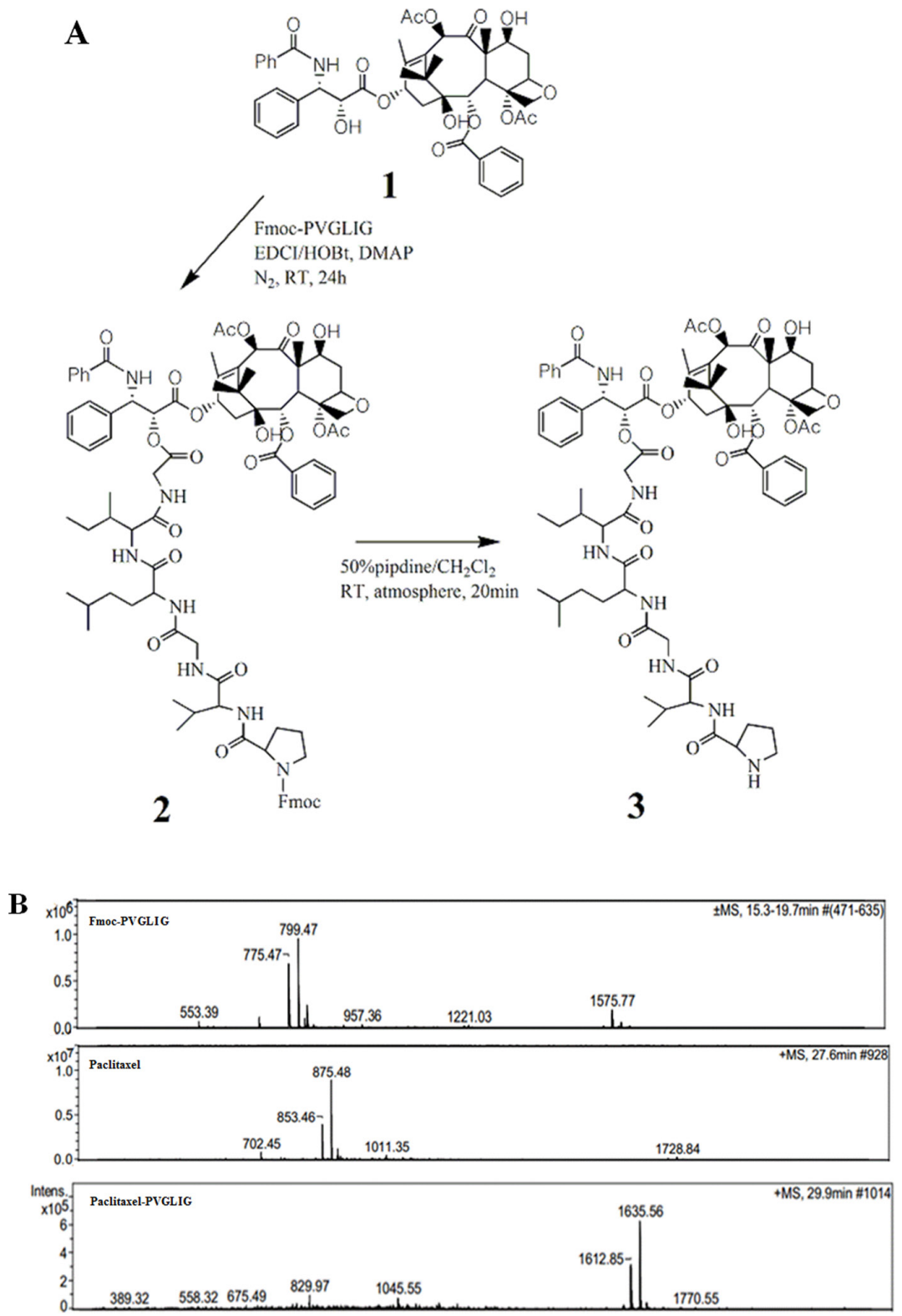

Figure 1: Synthesis of conjugate. (A) Synthetic scheme of conjugate (B) Mass spectra observed in synthesis procedure. Legend: Peptide was prepared containing an N-terminal Fmoc protection group in order to avoid the by-product. The Fmoc group is removed finally using traditional protocol. The samples were analyzed for ascertain the intermediate and final product (1428.34) using mass spectrometry. Conditions: Fmoc-PVGLIG was synthesized using solid phase peptide synthesis protocol and the purified product was then reacted with free paclitaxel. The final product was purified by RP-HPLC with XBridge C18 silica column and ascertained by HPLC-MS. 
in Table 1, result indicated that the conjugate exhibited improved cell viability against HT-1080 and U87MG tumor cells compared to paclitaxel control. In coincidence, there were no remarkable differences observed from Hep-2 and Hep G2 cell lines treated with conjugate or paclitaxel alone.

As known, MMP2 plays a critical role in tumour progression, tumour angiogenesis and metastasis; thus a cellular scratch assay was performed for investigating the metastasis inhibition of conjugate. In Figure 3, paclitaxel exhibited anti-proliferative activity against almost all tumour cell lines without any selectivity. However, the metastasis inhibiting rate in HT-1080 and U87MG cells followed treatment of conjugate was increased significantly than that of paclitaxel (Panel A and B in Figure 3).

To evaluate the anti-tumour effect of conjugate and free paclitaxel, the mice bearing with tumours derived from either HT-1080 or U87MG cells were treated with conjugate (15 mg paclitaxel/kg body weight/5 day) and free paclitaxel (15 mg/kg body weight/5 day), respectively. The antitumor activities were determined by monitoring the animal survival rate during 30 days treatment. The results in Figure 4 revealed that the administration of conjugate significantly increased the survival rate of experimental mice.

In summary, an MMP2 associated drug release system was developed based on a novel MMP2 specific peptide substrate in this study. The hexapeptide, PVGLIG, was conjugated with paclitaxel at $\mathrm{COOH}$-terminal of peptide. This conjugate is capable to release paclitaxel for its conventional cytotoxic activity upon the presence of MMP2. This novel drug release system was considered to increase the therapeutic index of paclitaxel due to the enhanced specific targeting activity.
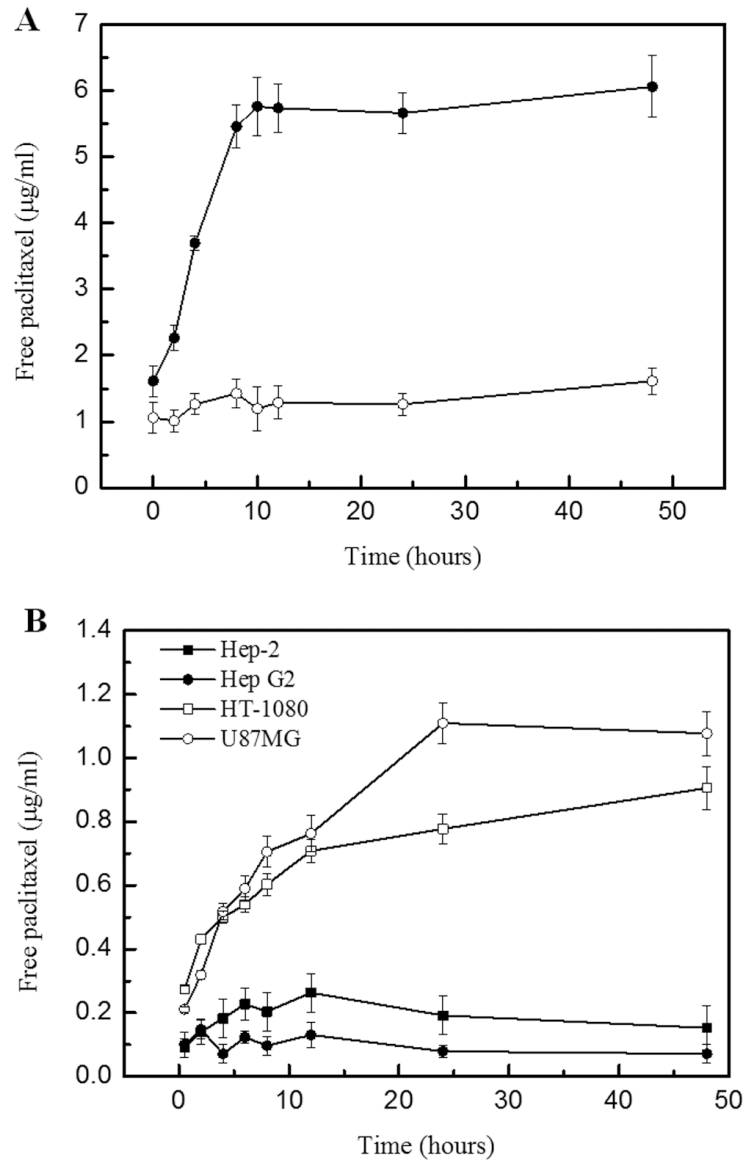

Figure 2: Paclitaxel dissociated from conjugate in MMP2 solution and various cell lines. (A) Concentration of released paclitaxel from conjugate upon the MMP2 proteolysis (B) Concentration of released paclitaxel from conjugate incubating within various cell lines. Legend: Result indicated that the presence of MMP2 enzyme induced the release of paclitaxel from conjugate significantly. The conjugate initiated the drug release at $2 \mathrm{~h}$ after incubation with MMP2 and the level of dispatched paclitaxel peaked to plateau at $12 \mathrm{~h}$ (Panel A). In addition, the conjugate was incubated with various cell lines and the released paclitaxel was monitored by HPLC-MS. Results indicated that the conjugate showed different drug dissociation characterization in various tumor cell lines. The MMP2 over expression tumor cells, HT-1080 and U87MG, induced the release of paclitaxel remarkably, compared with those from Hep-2 and Hep G2 cells (Panel B). The data confirmed that conjugate exhibited the presumed MMP2 sensitive activity. Condition: Conjugate containing $100 \mu \mathrm{g}$ paclitaxel were incubated with MMP2 $(5 \mu \mathrm{g})$ in PBS buffer, $\mathrm{Ph} 7.0$ containing $100 \mu \mathrm{M} \mathrm{ZnSO}_{4}$ at $37^{\circ} \mathrm{C}$ for 48 h-experimental period. Various cells were seed in 96-well plate, and conjugate containing $10 \mu \mathrm{g}$ paclitaxel was titrated into each well for incubation at various experimental periods. HPLC-MS was then employed to monitor the released free paclitaxel. 




Figure 3: Conjugate exhibited remarkable anti-proliferation activity on specific tumor cells. (A) Scratch assay of free paclitaxel and conjugate on HT-1080 cells (B) Scratch assay of free paclitaxel and conjugate on U87MG cells (C) Scratch assay of free paclitaxel and conjugate on Hep-2 cells (D) Scratch assay of free paclitaxel and conjugate on Hep G2 cells. Legend: Compared with the original migration inhibition effect of free paclitaxel in HT-1080 and U87MG cells, the conjugates presented a 1.4-fold and 1.7-fold increase on anti-migration activity, respectively. However, the conjugate failed to show anti-migration activity on Hep-2 and and Hep G2 cells those non-expressing MMP2. It was assumed that the inhibitory activity of conjugate on the cellular migrating phenotype is due to the specific release of paclitaxel upon the presence of MMP2 enzyme. Condition: The HT-1080, U87MG, Hep G2 and Hep-2 cell lines were plated in 6-well plates and cultured overnight respectively. The cell monolayer was scraped in a straight line with a sterile p200 pipette tip, the debris were removed by gently flushed with PBS twice. After rinsing, $2.5 \mathrm{~mL}$ cell supernatant (supplemented with 5\% FBS) containing either paclitaxel or conjugate (final concentration of each treatment drug at $5 \mathrm{mg} / \mathrm{ml}$ ) was covered on the scraped cells and then incubated cells at $37^{\circ} \mathrm{C}, 5 \% \mathrm{CO}_{2}$ for 24 hours. The distances of cellular edges were measured by using LEICA ICC50 HD microscopy (LEICA Microsystems Ltd, Switzerland). 
Table 1: MTT assay of conjugate in tumor cells, in comparison with that of free paclitaxel

\begin{tabular}{|c|c|c|c|c|}
\hline \multirow[b]{2}{*}{ Time } & \multicolumn{2}{|c|}{ HT-1080 } & \multicolumn{2}{|c|}{ U87MG } \\
\hline & Paclitaxel & Conjugate & Paclitaxel & Conjugate \\
\hline $24 \mathrm{~h}$ & $19.71 \pm 2.61$ & $42.73 \pm 2.69$ & $21.18 \pm 2.94$ & $38.15 \pm 1.82$ \\
\hline $48 \mathrm{~h}$ & $28.48 \pm 3.11$ & $53.16 \pm 1.85$ & $36.85 \pm 4.27$ & $62.16 \pm 3.04$ \\
\hline $72 \mathrm{~h}$ & $37.89 \pm 2.19$ & $84.24 \pm 2.43$ & $50.17 \pm 2.64$ & $87.83 \pm 4.26$ \\
\hline & \multicolumn{2}{|c|}{ Hep-2 } & \multicolumn{2}{|c|}{ Hep G2 } \\
\hline Time & Paclitaxel & Conjugate & Paclitaxel & Conjugate \\
\hline $24 \mathrm{~h}$ & $21.05 \pm 2.45$ & $22.74 \pm 3.62$ & $20.99 \pm 1.93$ & $17.54 \pm 1.03$ \\
\hline $48 \mathrm{~h}$ & $30.65 \pm 3.45$ & $27.85 \pm 3.75$ & $45.35 \pm 3.04$ & $20.11 \pm 2.65$ \\
\hline $72 \mathrm{~h}$ & $46.76 \pm 3.84$ & $30.15 \pm 3.85$ & $51.34 \pm 3.96$ & $34.74 \pm 2.94$ \\
\hline
\end{tabular}

Condition: The cells $\left(1 \times 10^{5}\right.$ cells $/ 100 \mu \mathrm{l} /$ well $)$ were seeded in 96 -well plates at $37^{\circ} \mathrm{C}$ and $5 \% \mathrm{CO}_{2}$. An aqueous solution of free paclitaxel and conjugate containing $10 \mu \mathrm{g}$ paclitaxel were added in the culture medium following MTT assay protocol. Legend: In MTT assay, the anti-proliferative activity of conjugate was confirmed to be MMP2 specific. In HT-1080 and U87MG cell lines, where MMP2 was highly expressed, the treatment of conjugate resulted in significant loss of cell viability, compared to Hep-2 or Hep-G2 cells with less MMP2 expression.
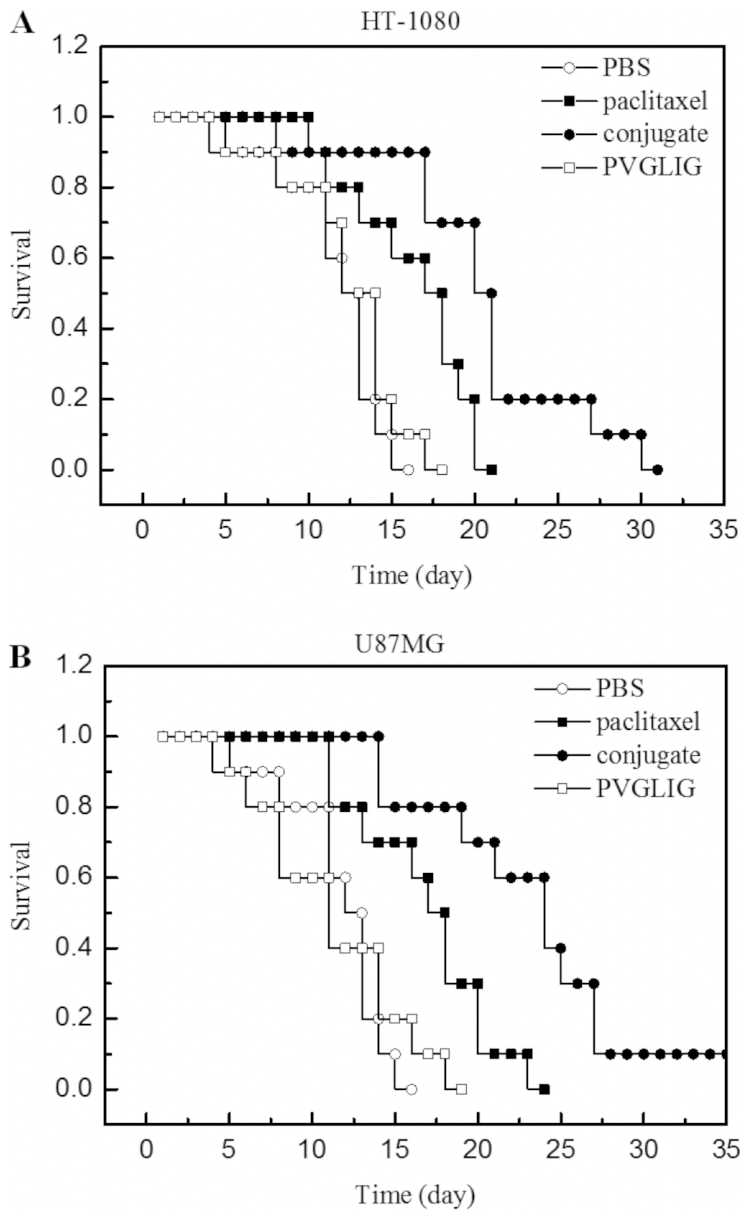

Figure 4: Anti-tumor efficacy of conjugate on human tumor bearing mice. (A) Effect of conjugate on human xenograft tumor model mice bearing HT-1080 cells (B) Effect of conjugate on human xenograft tumor model mice bearing U87MG cells. Legend: Results indicated that the conjugate $(\bullet)$ exhibited an improved survival time compared to free paclitaxel ( $\bullet$ ) in either HT-1080 (Panel A) or U87MG (Panel B) bearing mice, $p<0.05(n=10)$. Condition: Xenograft mice bearing HT-1080 and U87MG were treated with the conjugate and free paclitaxel, respectively. Survival time was recorded in days after tumour injection. All data obtained for repeated experiments were pooled and utilized for statistical analysis. 


\section{MATERIALS AND METHODS}

\section{Materials}

Fmoc-amino acids and resins in this study were purchased from GL Biochem Ltd. (Shanghai; HPLCpurified; purity $>99 \%$, identified by mass spectra). Paclitaxel was obtained from Demochem Co (Shanghai, China). All other chemicals were obtained from SigmaAldrich unless otherwise noted. The human recombinant MMP2 was purchased from Biomol International, Inc (Plymouth, PA).

\section{Cell culture}

The HT-1080, Hep G2 and MCF-7 cells were cultured in DMEM (Gibco by Invitrogen, California, USA) supplemented with $10 \%$ fetal bovine serum (Gibco by Invitrogen, California, USA). The U87MG cells were cultured in MEM (Gibco by Invitrogen, Carlsbad, California, USA) and RPMI-1640 (Gibco by Invitrogen, Carlsbad, California, USA) supplemented with $10 \%$ fetal bovine serum (Gibco by Invitrogen, California, USA). All cell lines were cultured at $37^{\circ} \mathrm{C}$ in an atmosphere of $5 \% \mathrm{CO}_{2}$.

\section{Synthesis of peptide (Fmoc-PVGLIG) and conjugate}

The peptide was synthesized by solid-phase synthesis using a CEM Liberty 1 peptide synthesizer. The synthesized peptide was purified by reverse phase HPLC equipped with a $\mathrm{C} 18$ column (XBridge, $5 \mu \mathrm{m}$ particle size, $10 \times 100 \mathrm{~mm}$; Waters, USA). The purified sample was evaluated by mass spectrometry. In brief, $12.5 \mathrm{mg}$ EDCI $(66.1 \mu \mathrm{mol})$ and $8.8 \mathrm{mg} \mathrm{HOBt}(66.1 \mu \mathrm{mol})$ were titrated into a paclitaxel solution $(56.5 \mathrm{mg}, 66.1 \mu \mathrm{mol})$ followed by the addition of $2 \mathrm{mg}$ DMAP after 15 minutes of stirring under nitrogen atmosphere at ambient temperature. After another 5 minutes of stirring, the peptide $(77.5 \mathrm{mg}$, $99.7 \mu \mathrm{mol}$ ) was added and then stirred for 24 hours. The reaction mixture was dried under reduced pressure following piperidine treatment for the removal of Fmoc group. RP-HPLC using an XBridge $\mathrm{C} 18$ silica column $(5 \mu \mathrm{m}$ particle size, $10 \times 100 \mathrm{~mm}$; Waters, USA) was employed to purify the peptide-drug conjugate using acetonitrile:water as the mobile phase. A linear gradient was applied; $0 \mathrm{~min}, 10 \%$ acetonitrile; $30 \mathrm{~min}, 90 \%$ acetonitrile at $214 \mathrm{~nm}$; the elution was collected and analysed.

\section{Cell growth inhibiting studies}

The cytotoxicity of free paclitaxel and conjugate were determined by an MTT assay using HT-1080, Hep-2, Hep G2 and U-87MG cell lines. The cells $\left(1 \times 10^{5}\right.$ cells/ $100 \mu \mathrm{l} /$ well) were seeded in 96 -well plates and cultured at $37^{\circ} \mathrm{C}$ and $5 \% \mathrm{CO}_{2}$, respectively. Free paclitaxel or conjugate was incubated with cells at final concentrations of $0.1,0.5,1$, 5,10 and $100 \mu \mathrm{g} / \mathrm{ml}$. The MTT solution ( $5 \mathrm{mg} / \mathrm{ml}$ in PBS) was titrated into each well after an incubation period of either 24, 48 or 72 hours. A traditional MTT protocol was performed, and cell viability was calculated.

\section{Scratch assay}

The special function of MMP2 in cancer metastasis suggests that halt of MMPs activity is capable to cease the tumor cell metastasis. In this study, scratch assays were conducted in order to investigate whether the conjugate is able to inhibit the metastasis, given the increased paclitaxel concentration surrounding the tumour cells upon proteolysis by MMP2 specifically.

The HT-1080, U87MG, Hep G2 and Hep-2 cells were seeded in 6-well plates and cultured overnight. Following scraping of the cell layers in a straight line by a sterile p200 pipette tip, the debris was removed in two gentle rinses with PBS. Subsequently, $2.5 \mathrm{ml}$ cell culture containing either free paclitaxel or conjuagte (final concentration at $5 \mu \mathrm{g} / \mathrm{ml}$ for paclitaxel) was plated. After 24 hours in a cell incubator, the distances between the two edges of the scratched cells were observed using Leica ICC50 HD microscopy (LEICA Microsystems Ltd, Switzerland). The apparent rate of inhibition was calculated using the following formula: inhibition rate (IR) $=\left[\left(\right.\right.$ Distance $_{\text {treated, } 24 \mathrm{~h}}-$ Distance $\left._{\text {treated, } 0 \mathrm{~h}}\right)-\left(\right.$ Distance $_{\text {control, } 24 \mathrm{~h}}$ Distancecontrol, 0 h)] $/$ Distance $_{\text {treated, } 0 \mathrm{~h}} \times 100$.

\section{Drug release study upon MMP2 proteolysis}

To determine whether the specific MMP2 proteolysis induced the release of paclitaxel or not, HPLCMS was employed to monitor the conjugate dissociation at the presence of the MMP2. Free paclitaxel $(100 \mu \mathrm{g})$ or conjugate (paclitaxel amount is $100 \mu \mathrm{g}$ ) solution was prepared in PBS buffer, $\mathrm{pH} 7.0$, containing $100 \mu \mathrm{M}$ $\mathrm{ZnSO} 4$ in various concentrations, following MMP2 $(5 \mu \mathrm{g})$ titration. The release of free paclitaxel in the mixture at different time points ( $2 \mathrm{~h}, 4 \mathrm{~h}, 8 \mathrm{~h}, 12 \mathrm{~h}$ and $24 \mathrm{~h}$ ) was monitored by RP-HPLC. A similar assay was also performed in cancer cell lines over-expressing MMP2 and in cancer cell lines without MMP2 expression.

\section{HPLC-MS measurement}

Three ThermoFinnigan quadrupole mass spectrometers (TSQ7000) with XCALIBUR and LCQUAN software were equipped with an electrospray ion source and a divert valve. The chromatographic system consisted of an HPLC pump (model 616) and Controller $616 \mathrm{~S}$ from Waters (Milford, MA, USA) and an autosampler Series 200 from PerkinElmer (Norwalk, CT, USA). The Oasis HLB chromatography column 
(30 $\mathrm{mm}$ particle size, $1 \times 50 \mathrm{~mm}$ ) from Waters was used. Electrospray-ionisation was performed in positive ion mode. The heated capillary was set at $245^{\circ} \mathrm{C}$ and the spray voltage at $4.5 \mathrm{kV}$. Nitrogen was used as the sheath and auxiliary gas and set at $90 \mathrm{lb} /$ square inch and 25 arbitrary units, respectively. The argon collision gas pressure was set to $2.5 \mathrm{mTorr}$. The samples $(50 \mu \mathrm{l})$ were chromatographed at ambient temperature on the Oasis HLB column. Solvent A was acetonitrile, and Solvent B was $5 \mathrm{mM}$ sodium trifluoroacetate in $0.1 \%$ aqueous formic acid. The analyses were chromatographed with a $0.8 \mathrm{ml} /$ min flow rate with the following linear gradient: $0 \mathrm{~min}$, $5 \%$ A; $0.5 \mathrm{~min}, 5 \% \mathrm{~A} ; 5.5 \mathrm{~min}, 82 \%$ A. The gradient was followed by a $1.0 \mathrm{ml} / \mathrm{min}$ rinse for $1.0 \mathrm{~min}$ with $100 \%$ methanol and $30 \mathrm{~s}$ with $95 \%$ acetonitrile and by column re-equilibration to the initial conditions. The flow was diverted to the mass spectrometer for quantitative analysis.

\section{Treatment of human tumour xenograft mice}

Six-week-old male BALB/c nude mice were obtained from Shanghai Laboratory Animal Co., China Academy of Sciences (Shanghai, China). Mice (weighing $16-20 \mathrm{mg}$ ) were housed in barrier facilities on a $12 \mathrm{~h}$ light/ dark cycle. Food and water were supplied ad libitum. On day zero, two groups of mice were inoculated via i.p. injection with HT-1080 and U-87MG tumour cells $\left(2 \times 10^{5}\right)$ in $0.5 \mathrm{ml}$ of RPMI1640. Treatment was initiated after the tumour was allowed to grow to approximately $100 \mathrm{~mm}^{3}$ on the back of the mouse. This experimental protocol is intended to mimic the clinical situation when treatment begins after the tumour has already been established in the treatment of human tumour xenograft mice. The animals were treated with free paclitaxel or conjugate at the specified dose (15 $\mathrm{mg} / \mathrm{kg}$ body weight) every 5 days. Control groups were treated with PVGLIG. During the experimental period of 30 days, the survival ratio was recorded in days after tumour injection. The mean and median survival time and the statistical significance of the results were determined by employing a two-tailed Wilcoxon's ranking test.

\section{Statistics}

All data in this paper were presented as mean \pm SD. The statistical significance was analysed using a two-tailed Wilcoxon's ranking test, and $P<0.05$ was considered statistically significant.

\section{CONCLUSIONS}

Paclitaxel is a widely used chemotherapeutic agent in the clinical treatment of various solid tumor including ovarian, breast, non-small cell lung, head and neck cancers. However, the off-target toxicity of paclitaxel restricted its clinical utility.

In this study, paclitaxel was successfully conjugated with a hexapeptide which is recognized by MMP2 specifically, the interaction of hexapeptide and MMP2 enzymatic pocket showed in Figure 5. Consequently, MMP2 enzymatically hydrolysed the hexapeptide and

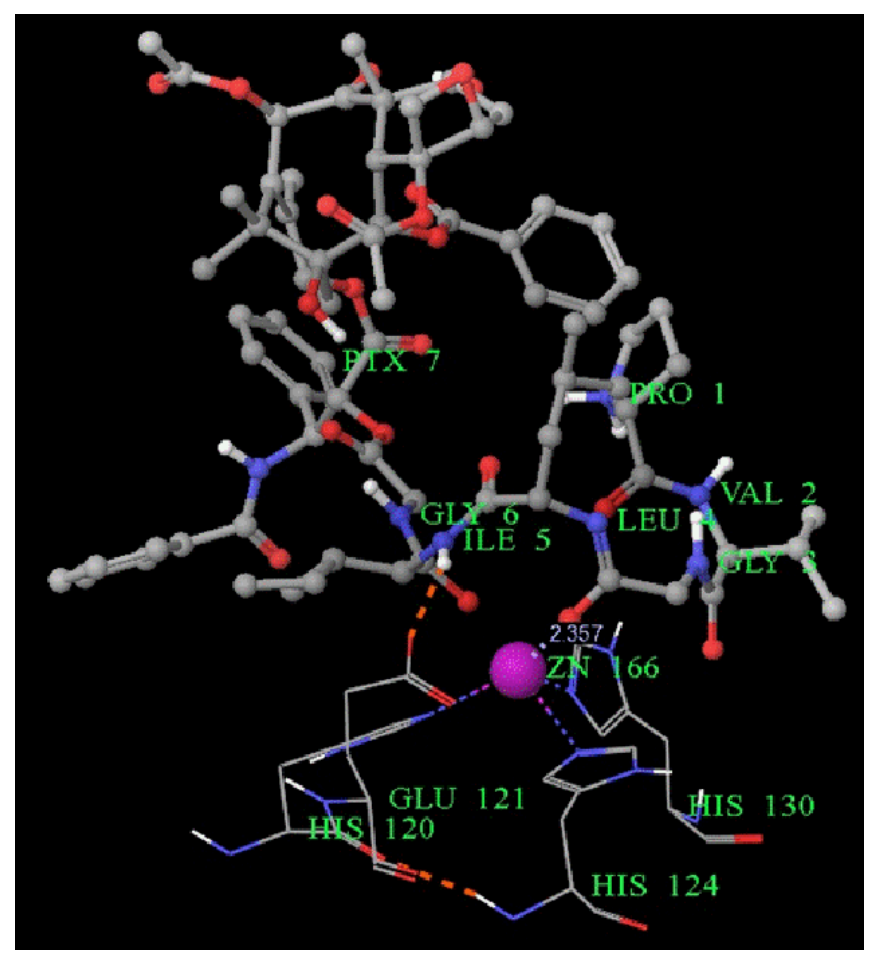

Figure 5: The molecular model of the interaction of conjugate and MMP2 protein. Legend: The Leu4, Ile5 and Gly6 residues interact with Zn2+ binding site in MMP2 protein, the residue His120, His 124, His130 and His 166. 
then release the paclitaxel molecule. This conjugate was considered to be a powerful approach for inhibiting the tumour growth and metastasis in tumor with high expression of MMP2.

\section{ACKNOWLEDGMENTS AND FUNDING}

This study was supported by the National Science and Technology Major Project of the Ministry of Science and Technology of China (2014ZX09507005-003), the National Natural Science Funding (81400932), Major Project of Science and Technology of Tianjin (13RCGFSY19700) and the Natural Science Foundation of Tianjin, China (12JCYBJC31500).

\section{CONFLICTS OF INTEREST}

The authors have no conflicts of interest.

\section{Authors' contributions}

Dr. CH.H performed the partial conjugate synthesis and cellular assay including scratch assay, MTT assay. Dr. X.Y fulfilled the experiment in human tumour xenograft mice, and Dr. D.K conducted the peptide synthesis, drug conjugation and the HPLC-MS study. Prof. L.CH discussed the result and conclusion. Dr. M.G wrote the manuscript.

\section{REFERENCES}

1. Bernhard EJ, Hagner B, Wong C, Lubenski I, Muschel RJ. The effect of E1A transfection on MMP-9 expression and metastatic potential. Int J Cancer. 1995; 60:718-724.

2. Paez Pereda M, Ledda MF, Goldberg V, Chervin A, Carrizo G, Molina H, Muller A, Renner U, Podhajcer O, Arzt E, Stalla GK. High levels of matrix metalloproteinases regulate proliferation and hormone secretion in pituitary cells. J Clin Endocrinol Metab. 2000; 85:263-269.

3. Winding B, NicAmhlaoibh R, Misander H, HoeghAndersen P, Andersen TL, Holst-Hansen C, Heegaard AM, Foged NT, Brunner N, Delaisse JM. Synthetic matrix metalloproteinase inhibitors inhibit growth of established breast cancer osteolytic lesions and prolong survival in mice. Clin Cancer Res. 2002; 8:1932-1939.

4. Nold M, Goede A, Eberhardt W, Pfeilschifter J, Muhl H. IL-18 initiates release of matrix metalloproteinase-9 from peripheral blood mononuclear cells without affecting tissue inhibitor of matrix metalloproteinases-1: suppression by TNF alpha blockage and modulation by IL-10. Naunyn Schmiedebergs Arch Pharmacol. 2003; 367:68-75.

5. Klein G, Vellenga E, Fraaije MW, Kamps WA, de Bont ES. The possible role of matrix metalloproteinase (MMP)-2 and MMP-9 in cancer, e.g. acute leukemia. Crit Rev Oncol Hematol. 2004; 50:87-100.
6. Rizvi NA, Humphrey JS, Ness EA, Johnson MD, Gupta E, Williams K, Daly DJ, Sonnichsen D, Conway D, Marshall J, Hurwitz H. A phase I study of oral BMS-275291, a novel nonhydroxamate sheddase-sparing matrix metalloproteinase inhibitor, in patients with advanced or metastatic cancer. Clin Cancer Res. 2004; 10:1963-1970.

7. Mu S, Liu Y, Gong M, Liu DK, Liu CX. Synthesis and biological evaluation of substituted desloratadines as potent arginine vasopressin V2 receptor antagonists. Molecules. 2014; 19:2694-2706.

8. Andey T, Patel A, Jackson T, Safe S, Singh M. 1,1-Bis (3'-indolyl)-1-(p-substitutedphenyl)methane compounds inhibit lung cancer cell and tumor growth in a metastasis model. Eur J Pharm Sci. 50:227-241.

9. Raghuwanshi SK, Smith N, Rivers EJ, Thomas AJ, Sutton N, Hu Y, Mukhopadhyay S, Chen XL, Leung T, Richardson RM. G protein-coupled receptor kinase 6 deficiency promotes angiogenesis, tumor progression, and metastasis. J Immunol. 190:5329-5336.

10. $\mathrm{Hu} \mathrm{J}, \mathrm{Chen} \mathrm{C}, \mathrm{Su} \mathrm{Y}, \mathrm{Du}$ J, Qian X, Jin Y. Vascular endothelial growth factor promotes the expression of cyclooxygenase 2 and matrix metalloproteinases in Lewis lung carcinoma cells. Exp Ther Med. 4:1045-1050.

11. Shukla S, MacLennan GT, Fu P, Gupta S. Apigenin attenuates insulin-like growth factor-I signaling in an autochthonous mouse prostate cancer model. Pharm Res. 29:1506-1517.

12. Peng CW, Liu XL, Liu X, Li Y. Co-evolution of cancer microenvironment reveals distinctive patterns of gastric cancer invasion: laboratory evidence and clinical significance. J Transl Med. 8:101.

13. Shi NQ, Gao W, Xiang B, Qi XR. Enhancing cellular uptake of activable cell-penetrating peptide-doxorubicin conjugate by enzymatic cleavage. Int J Nanomedicine. 7:1613-1621.

14. Lee GY, Park K, Kim SY, Byun Y. MMPs-specific PEGylated peptide-DOX conjugate micelles that can contain free doxorubicin. Eur J Pharm Biopharm. 2007; 67:646-654.

15. Bae M, Cho S, Song J, Lee GY, Kim K, Yang J, Cho K, Kim SY, Byun Y. Metalloprotease-specific poly(ethylene glycol) methyl ether-peptide-doxorubicin conjugate for targeting anticancer drug delivery based on angiogenesis. Drugs Exp Clin Res. 2003; 29:15-23.

16. Bansal R, Prakash J, de Ruijter M, Beljaars L, Poelstra K. Peptide-modified albumin carrier explored as a novel strategy for a cell-specific delivery of interferon gamma to treat liver fibrosis. Mol Pharm. 2011; 8:1899-1909.

17. Cobos-Correa A, Stein F, Schultz C. Target-Activated Prodrugs (TAPs) for the Autoregulated Inhibition of MMP12. ACS Med Chem Lett. 2012; 3:653-657.

18. Chau Y, Dang NM, Tan FE, Langer R. Investigation of targeting mechanism of new dextran-peptide-methotrexate conjugates using biodistribution study in matrixmetalloproteinase-overexpressing tumor xenograft model. J Pharm Sci. 2006; 95:542-551. 
19. Chau Y, Padera RF, Dang NM, Langer R. Antitumor efficacy of a novel polymer-peptide-drug conjugate in human tumor xenograft models. Int J Cancer. 2006; 118:1519-1526.

20. Chau Y, Tan FE, Langer R. Synthesis and characterization of dextran-peptide-methotrexate conjugates for tumor targeting via mediation by matrix metalloproteinase II and matrix metalloproteinase IX. Bioconjug Chem. 2004; 15:931-941. 